\title{
AUDITORIA TÉCNICA PARA AVALIAÇÃO DE CAMINHABILIDADE
}

\section{TECHNICAL AUDIT TO EVALUATE WALKABILITY}

\author{
$<$ Isabela Batista Pires $>^{1}$, M. $^{a}$ \\ $<$ Heloísa de Freitas Zanella Rossetto $>^{2}$, M. ${ }^{\text {a }}$ \\ $<$ Fábio Albert Basso $>^{3}$, Esp. \\ $<$ Renata Cardoso Magagnin $>^{4}$, Dra. \\ $<$ Obede Borges Faria $>^{5}$, Dr.
}

(1) Universidade Estadual Paulista "Julio de Mesquita Filho" (UNESP-PPGARQ) e-mail: isabelaba@gmail.com

(2) Universidade Estadual Paulista “Julio de Mesquita Filho” (UNESP-PPGARQ) e-mail: heloisa_zanella@hotmail.com

(3) Universidade Paulista (UNIP)

e-mail: fabioalbertbasso@yahoo.com.br

(4) Universidade Estadual Paulista “Julio de Mesquita Filho” (UNESP-PPGARQ) e-mail:magagnin@faac.unesp.br

(5) Universidade Estadual Paulista “Julio de Mesquita Filho” (UNESP-PPGARQ) e-mail: obede.faria@gmail.com

Palavras-chave: Caminhabilidade, Auditoria técnica, Infraestrutura de pedestre.

Este artigo visa apresentar o resultado da aplicação de uma proposta metodológica para mensurar a caminhabilidade por meio da adaptação de métodos de auditoria técnica existentes. Os resultados encontrados apontam para a validade do método proposto. Sugere-se sua aplicação em outros percursos e recortes espaciais, como forma de consolidar sua validação.

\section{Key-words: Walkability, Technical audit, Pedestrian infrastructure.}

This paper presents the result of the application of a methodological proposal to measure the walkability through the adaptation of existing technical audit methods. The results found point to the validity of the proposed method. It is suggested to apply it in other pathways and spatial area, as a way to consolidate its validation. 
$16^{\circ}$ Ergodesign - Congresso Internacional de Ergonomia e Usabilidade de Interfaces Humano Tecnológica: Produto, Informações Ambientes Construídos e Transporte

$16^{\circ}$ USIHC - Congresso Internacional de Ergonomia e Usabilidade de Interfaces Humano Computador

CINAHPA | 2017 - Congresso Internacional de Ambientes Hipermídia para Aprendizagem.

\section{Introdução}

O deslocamento a pé, ou caminhada, é um dos modos de transporte mais importante nas cidades que buscam implantar o conceito de mobilidade sustentável [GORI; NIGRO; PETRELLI, 2014; GUO; LOO, 2013; YOSHIDA; ALONGE; MAGAGNIN, 2016]. Por esse motivo, muitos municípios brasileiros têm colocado em debate a qualidade da infraestrutura ofertada aos pedestres, em especial, por aquelas pessoas que possuem alguma deficiência ou mobilidade reduzida [LANCHOTI; BRUNA, 2010].

Quando a cidade proporciona infraestrutura adequada aos pedestres, o número de deslocamentos por modo a pé aumenta [SARKAR, 2003]. O caminhar abre espaço para que ocorra interação social [SPECK, 2016] e permite que a cidade cumpra sua função social, como local de encontro [GEHL, 2015].

Pesquisadores da área de transporte e mobilidade sustentável têm utilizado o termo caminhabilidade (walkability, em inglês) para mensurar a qualidade dos espaços de circulação destinados aos pedestres [PIRES; GEBARA; MAGAGNIN, 2016].

A caminhabilidade deve proporcionar sensação de segurança e conforto aos pedestres [SPECK, 2016]. O aumento do grau de caminhabilidade ou da qualidade da infraestrutura oferecida aos pedestres possibilita que um número maior de pessoas possam se movimentar nos espaços de uso público e, assim, permanecer mais tempo na rua, o que pode aumentar a seguridade das cidades [GEHL, 2015].

Diversos trabalhos foram elaborados para determinar quais fatores do ambiente construído interferem na qualidade das viagens a pé [MORI; TSUKAGUCHI, 1987; KHISTY, 1994; LANDIS et al., 2001; SARKAR, 2003;

MURALEETHARAN, 2004]. No entanto, muitas destas pesquisas que utilizam auditoria técnica envolvem cálculos complexos, requerem dados de difícil acesso ou obtenção e são compostas de tabelas muito extensas, como é o caso do Irvine Minnesota Inventory [BOARNET et al., 2006; DAY et al.; 2006], com 162 indicadores.

Em comum, estes autores utilizaram atributos de avaliação como largura da calçada, arborização, presença de obstáculos, condições da superfície de caminhada, conflitos entre pedestres e veículos, ambientes com boa visibilidade, qualidade da iluminação pública, facilidades de travessia (como boa visibilidade das marcações de travessias, presença de rebaixos de calçada e piso tátil de alerta), entre outros.

Estes atributos são indicadores que permitem mensurar o desempenho dos espaços urbanos e podem determinar a qualidade da caminhabilidade [FERRAZ; TORRES, 2004; FONTENELLE et al., 2008]. Nestas pesquisas, as escalas finais de avaliação de classificação do grau da qualidade da caminhabilidade foram: somatório final do valor dos indicadores (com comparação da nota obtida em campo com as notas da melhor situação) e classificação de nível de serviço.

A partir das pesquisas anteriormente citadas, este artigo buscou utilizar uma metodologia menos complexa e mais prática para mensurar a caminhabilidade, que pudesse ser replicada por técnicos e especialistas da administração pública e que avaliasse estes mesmos aspectos considerados importantes para a qualidade da infraestrutura para pedestres. A identificação dos diversos problemas que podem comprometer a caminhabilidade permite que os gestores locais possam intervir antecipadamente e assim garantir uma maior segurança dos pedestres.

Diante do exposto, este artigo visa apresentar o resultado da aplicação de uma proposta metodológica para mensurar a caminhabilidade por meio da adaptação de métodos de auditoria técnica existentes.
Realização:
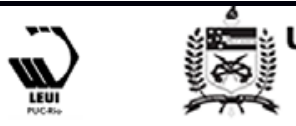


\section{$16^{\circ}$ \\ ERGODESIGN USIHC CINAHPA}

\section{Metodologia}

Para identificar quais fatores podem prejudicar a caminhabilidade no percurso, objeto de estudo, foram adotados os seguintes procedimentos metodológicos: auditoria técnica e levantamento fotográfico.

\subsection{Objeto de estudo}

A pesquisa foi realizada no ano de 2016, no município de Bauru, localizado na região centrooeste do Estado de São Paulo. O recorte espacial está situado na região sul da cidade. O percurso tem início no ponto de ônibus localizado na Av. Nações Unidas, em frente à Praça da Paz, e segue até a entrada principal do Bauru Shopping. No total, foram avaliadas 18 faces de quadra (Figura 1).

Este percurso foi selecionado devido à observação in loco do fluxo de pessoas em direção ao shopping nos horários de pico.

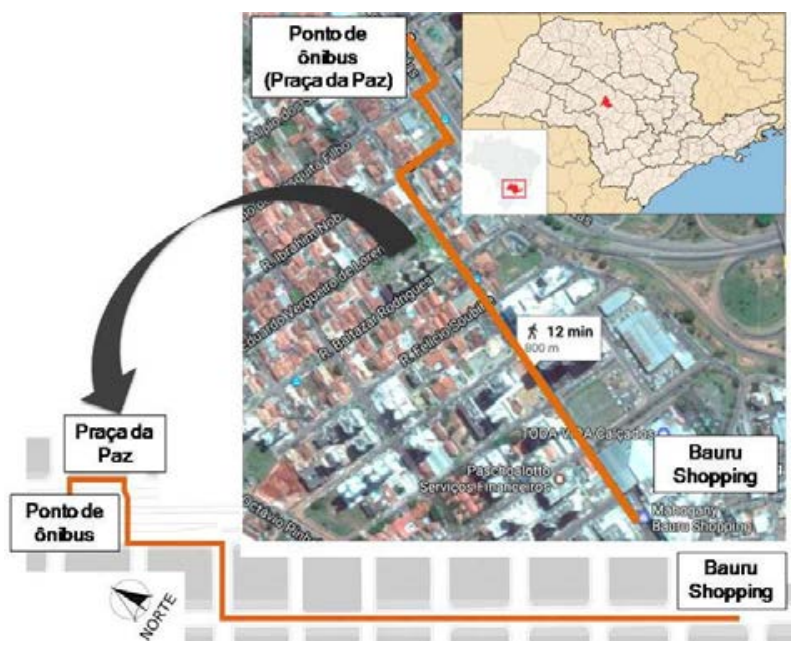

Figura 1 - Mapa da localização do município no Estado de São Paulo e da área de estudo (sem escala)

\subsection{Instrumentos metodológicos}

As variáveis selecionadas para identificar os fatores que afetam a caminhabilidade neste percurso foram selecionadas a partir do trabalho desenvolvido por Cerna [2014]. Os atributos $16^{\circ}$ Ergodesign - Congresso Internacional de Ergonomia e Usabilidade de Interfaces Humano Tecnológica: Produto, Informações Ambientes Construídos e Transporte

$16^{\circ}$ USIHC - Congresso Internacional de Ergonomia e Usabilidade de Interfaces Humano Computador

CINAHPA | 2017 - Congresso Internacional de Ambientes Hipermídia para Aprendizagem.

relacionados à infraestrutura de pedestres (neste artigo, denominados de Temas) foram: calçada, ponto de ônibus, abrigo de passageiros, rebaixo de calçada, faixa de pedestres, semáforo e rampa.

Cada Tema foi subdividido em Indicadores. No total foram avaliados 7 Temas e 69 Indicadores, assim distribuídos: Calçadas (16 indicadores), Ponto de ônibus (14 indicadores), Abrigos de passageiros (6 indicadores), Rebaixos de Calçada (13 indicadores), Faixas de pedestres ( 5 indicadores), Semáforos (5 indicadores) e Rampas (10 indicadores), Tabelas 1 a 7.

A escala numérica adotada para avaliação dos Indicadores na planilha de auditoria técnica é distinta, mas corresponde a um intervalo numérico correspondente a $0 ; 5$ e 10 ou 0 e 10 , no qual o valor 0 corresponde à pior avaliação e o valor 10 à melhor avaliação. Estes valores serão aferidos a partir da auditoria técnica em campo.

De acordo com a metodologia de Cerna [2014], os resultados dos Indicadores e Temas presentes na planilha de auditoria técnica devem ser multiplicados pelos seus respectivos pesos. Nesse método, cada Indicador possui pesos distintos cujos valores numéricos correspondem aos valores 1, 2 ou 3. O autor utilizou como referência para a definição desses pesos, aspectos relacionados à segurança e ao conforto dos pedestres. Os indicadores relacionados à segurança receberam peso 3 (indicadores associados a risco de acidente dos usuários, especialmente os de mobilidade reduzida), enquanto os relacionados ao conforto receberam peso 2 , devido à predominância da segurança sobre o conforto. Os indicadores cuja classificação não foi relacionada à segurança ou ao conforto receberam peso 1 .

As Tabelas 1 a 7 apresentam os Indicadores, agrupados por Tema, seus respectivos pesos (p), critérios de avaliação e valor máximo ideal.

\begin{tabular}{ll}
\hline Tema: CALÇADA & \\
\hline Indicadores e pesos & Critérios de avaliação \\
\hline Elementos mínimos da calçada & Faixa de serviço e faixa \\
$(\mathrm{p}=1)$ & livre: 10 \\
& Nenhuma: 0
\end{tabular}

Realização:
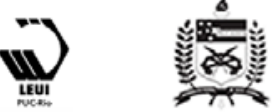
$16^{\circ}$ Ergodesign - Congresso Internacional de Ergonomia e Usabilidade de Interfaces Humano Tecnológica: Produto, Informações Ambientes ERGODESIGN Construídos e Transporte

$16^{\circ}$ USIHC - Congresso Internacional de Ergonomia e Usabilidade de Interfaces Humano Computador

CINAHPA | 2017 - Congresso Internacional de Ambientes Hipermídia para Aprendizagem.

\begin{tabular}{|c|c|}
\hline Tema: CALÇADA & \\
\hline Indicadores e pesos & Critérios de avaliação \\
\hline $\begin{array}{l}\text { Localização faixa de serviço } \\
(p=1)\end{array}$ & $\begin{array}{l}\text { Outra: } 0 \text {; } \\
\text { Adjacente ao meio-fio: } 10\end{array}$ \\
\hline $\begin{array}{l}\text { Largura de faixa livre ou passeio } \\
(\mathrm{Lfl})(\mathrm{p}=2)\end{array}$ & $\begin{array}{l}L f l<1,50 \mathrm{~m}: 0 \\
L f l \geq 1,50 \mathrm{~m}: 10\end{array}$ \\
\hline Superfície regular $(p=2)$ & Não: 0; Sim: 10 \\
\hline Superfície sem desníveis ( $\mathrm{p}=3$ ) & Não: 0; Sim: 10 \\
\hline Superfície firme e estável ( $p=3$ ) & Não: 0; Sim: 10 \\
\hline Superfície antiderrapante $(\mathrm{p}=3)$ & Não: 0; Sim: 10 \\
\hline $\begin{array}{l}\text { Superfície de fácil reposição } \\
(p=1)\end{array}$ & Não: 0; Sim: 10 \\
\hline $\begin{array}{l}\text { Inclinação longitudinal (il) } \\
(\mathrm{p}=2)\end{array}$ & $\begin{array}{l}\text { il }>5,00 \%: 0 \\
i l \leq 5,00 \%: 10\end{array}$ \\
\hline $\begin{array}{l}\text { Inclinação transversal (it) } \\
(\mathrm{p}=3)\end{array}$ & $\begin{array}{l}\text { it }>2,00 \%: 0 \\
\text { it } \leq 2,00 \%: 10\end{array}$ \\
\hline $\begin{array}{l}\text { Altura livre de obstáculos (Alo) } \\
(\mathrm{p}=2)\end{array}$ & $\begin{array}{l}\text { Alo <2,10m: } 0 \\
\text { Alo } \geq 2,10 \mathrm{~m}: 10\end{array}$ \\
\hline $\begin{array}{l}\text { Faixa desobstruída e isenta de } \\
\text { interferências }(p=3)\end{array}$ & Não: 0; Sim: 10 \\
\hline $\begin{array}{l}\text { Arborização nas vias arteriais } \\
(\mathrm{p}=2)\end{array}$ & Não: 0; Sim: 10 \\
\hline $\begin{array}{l}\text { Altura de meio-fio }(\mathrm{Hm} f) \\
(\mathrm{p}=2)\end{array}$ & $\begin{array}{l}H m f>0,18 \mathrm{~m}: 0 \\
H m f<0,10 \mathrm{~m}: 0 \\
0,10 \mathrm{~m} \leq H m f \leq 0,18 \mathrm{~m}: 10\end{array}$ \\
\hline $\begin{array}{l}\text { Nivelação com a calçada do lote } \\
\text { contíguo }(p=3)\end{array}$ & Não: 0; Sim: 10 \\
\hline Presença de iluminação (p =3) & Não: 0; Sim: 10 \\
\hline Valor máximo ideal & 360 \\
\hline
\end{tabular}

Tabela 1 - Indicadores do Tema Calçada. FONTE: Adaptado de Cerna [2014]

\begin{tabular}{|c|c|}
\hline \multicolumn{2}{|c|}{ Tema: PONTO DE ÔNIBUS (P.O.) } \\
\hline Indicadores e pesos & Critérios de avaliação \\
\hline $\begin{array}{l}\text { Sinalização tátil de alerta ao longo } \\
\text { do meio-fio }(\mathrm{p}=3)\end{array}$ & Não: 0; Sim: 10 \\
\hline $\begin{array}{l}\text { Piso tátil direcional no local } \\
\text { embarq./desembarq. }(\mathrm{p}=3)\end{array}$ & Não: 0; Sim: 10 \\
\hline $\begin{array}{l}\text { Comprimento mínimo de calçada } \\
(\text { Ссро) }(\mathrm{p}=2)\end{array}$ & $\begin{array}{l}\text { Ссро < 10m: } 0 \\
\text { Ссро } \geq 10 \mathrm{~m}: 10\end{array}$ \\
\hline $\begin{array}{l}\text { Largura mínima de calçada (Lcpo) } \\
(p=2)\end{array}$ & $\begin{array}{l}\text { Lсро < 2m: } 0 \\
\text { Lсpo } \geq 2 \mathrm{~m}: 10\end{array}$ \\
\hline $\begin{array}{l}\text { Presença de rampa de acesso } \\
(p=2)\end{array}$ & Não: 0; Sim: 10 \\
\hline Presença de meio-fio $(\mathrm{p}=3)$ & Não: 0; Sim: 10 \\
\hline $\begin{array}{l}\text { Presença de placa de sinalização } \\
\text { de ponto de ônibus }(p=3)\end{array}$ & Não: 0; Sim: 10 \\
\hline $\begin{array}{l}\text { Presença de ponto de iluminação } \\
\text { pública }(\mathrm{p}=3)\end{array}$ & Não: 0; Sim: 10 \\
\hline Presença de lixeira $(\mathrm{p}=1)$ & Não: 0; Sim: 10 \\
\hline Presença de árvore $(\mathrm{p}=2)$ & Não: 0; Sim: 10 \\
\hline $\begin{array}{l}\text { Presença de marcações } \\
\text { delimitadoras nas vias }(p=3)\end{array}$ & Não: 0; Sim: 10 \\
\hline Presença de baia $(p=3)$ & Não: 0; Sim: 10 \\
\hline $\begin{array}{l}\text { Profundidade de reentrância nas } \\
\text { calçadas }(\operatorname{Prc})(\mathrm{p}=3)\end{array}$ & $\begin{array}{l}\operatorname{Prc}<3,00 \mathrm{~m}: 0 \\
\operatorname{Prc} \geq 3,00 \mathrm{~m}: 10\end{array}$ \\
\hline $\begin{array}{l}\text { Presença de painel informativo do } \\
\text { Transporte Público }(p=1)\end{array}$ & Não: 0; Sim: 10 \\
\hline Valor máximo ideal & 330 \\
\hline
\end{tabular}

Tabela 2 - Indicadores do Tema Pontos de ônibus. FONTE: Adaptado de Cerna [2014]

\begin{tabular}{|c|c|}
\hline \multicolumn{2}{|c|}{ Tema: ABRIGO DE PASSAGEIROS (A.P) } \\
\hline Indicadores e pesos & Critérios de avaliação \\
\hline $\begin{array}{l}\text { Presença de assentos fixos para } \\
\text { descanso }(p=2)\end{array}$ & Não: 0; Sim: 10 \\
\hline $\begin{array}{l}\text { Espaço para pessoas com cadeiras } \\
\text { de rodas }(p=2)\end{array}$ & Não: 0; Sim: 10 \\
\hline $\begin{array}{l}\text { Espaço para pessoas com cadeiras } \\
\text { de rodas perto dos assentos }(\mathrm{p}=2)\end{array}$ & Não: 0; Sim: 10 \\
\hline $\begin{array}{l}\text { Largura do espaço } \mathrm{p} / \text { pessoas com } \\
\text { cadeiras de rodas (Lepcr) } \\
(\mathrm{p}=2)\end{array}$ & $\begin{array}{l}\text { Lepcr }<80 \mathrm{~cm}: 0 \\
\text { Lepcr }>80 \mathrm{~cm}: 5 \\
\text { Lepcr }=80 \mathrm{~cm}: 10\end{array}$ \\
\hline $\begin{array}{l}\text { Cumprimento do espaço } \mathrm{p} / \\
\text { pessoas com cadeiras de rodas } \\
(\text { Cepcr })(\mathrm{p}=2)\end{array}$ & $\begin{array}{l}\text { Cepcr }<120 \mathrm{~cm}: 0 \\
\text { Cepcr }>120 \mathrm{~cm}: 5 \\
\text { Cepcr }=120 \mathrm{~cm}: 10\end{array}$ \\
\hline Presença de cobertura $(\mathrm{p}=2)$ & Não: 0; Sim: 10 \\
\hline Valor máximo ideal & 120 \\
\hline
\end{tabular}

Tabela 3 - Indicadores do Tema Abrigos de passageiros. FONTE: Adaptado de Cerna [2014]

\begin{tabular}{|c|c|}
\hline \multicolumn{2}{|c|}{ Tema: REBAIXO DE CALÇADA (R.C.) } \\
\hline Indicadores e pesos & Critérios de avaliação \\
\hline $\begin{array}{l}\text { Localizado em local de travessias } \\
\text { de pedestres }(\mathrm{p}=3)\end{array}$ & Não: 0; Sim: 10 \\
\hline $\begin{array}{l}\text { Desnível entre parte inferior do } \\
\text { RC* e o leito carroçável }(H d) \\
(\mathrm{p}=2)\end{array}$ & $\begin{array}{l}H d=0 \\
H d \neq 0: 0\end{array}$ \\
\hline $\begin{array}{l}\text { Construídos na direção do fluxo de } \\
\text { pedestres }(p=1)\end{array}$ & Não: 0; Sim: 10 \\
\hline $\begin{array}{l}\text { Os RC em lados opostos da via } \\
\text { devem estar alinhados entre si } \\
(\mathrm{p}=3)\end{array}$ & Não: 0; Sim: 10 \\
\hline $\begin{array}{l}\text { Inclinação longitudinal do RC } \\
(i l r c) \quad(p=2)\end{array}$ & $\begin{array}{l}\text { ilrc > 8,33\%: } 0 \\
\text { ilrc } \leq 8,33 \%: 10\end{array}$ \\
\hline $\begin{array}{l}\text { Inclinação transversal do RC (itrc) } \\
(\mathrm{p}=2)\end{array}$ & $\begin{array}{l}i \operatorname{trc}>3,00 \%: 0 \\
i \operatorname{trc} \leq 3,00 \%: 10\end{array}$ \\
\hline $\begin{array}{l}\text { Presença de piso tátil de alerta } \\
(\mathrm{p}=3)\end{array}$ & Não: 0; Sim: 10 \\
\hline $\begin{array}{l}\text { Largura do piso tátil de alerta de } \\
\operatorname{RC}(\text { Lptrc })(\mathrm{p}=3)\end{array}$ & $\begin{array}{l}\text { Lptrc < 0,25m: 0; } \\
\text { Lptrc < 0,50m: 5; } \\
0,25 \mathrm{~m} \leq \text { Lptrc } \leq 0,5 \mathrm{~m}: 10\end{array}$ \\
\hline $\begin{array}{l}\text { Distância do RC dos pontos de } \\
\text { curva de esquinas (Drce) }(\mathrm{p}=3)\end{array}$ & $\begin{array}{l}\text { Drce }<3,5 \mathrm{~m}: 0 \\
\text { Drce } \geq 3,5 \mathrm{~m}: 10\end{array}$ \\
\hline $\begin{array}{l}\text { Largura faixa livre em frente a } \\
\text { rampa do RC ( } L f l r c)(\mathrm{p}=3)\end{array}$ & $\begin{array}{l}L f l r c<80 \mathrm{~cm}: 0 \\
L f l r c \geq 80 \mathrm{~cm}: 10\end{array}$ \\
\hline $\begin{array}{l}\text { Superfície do piso do RC com } \\
\text { material antiderrapante }(\mathrm{p}=3)\end{array}$ & Não: 0; Sim: 10 \\
\hline $\begin{array}{l}\text { Largura mínima de calçada para } \\
\operatorname{RC}(\operatorname{Lcrc})(\mathrm{p}=2)\end{array}$ & $\begin{array}{l}L c r c<2,10 \mathrm{~m}: 0 \\
L c r c \geq 2,10 \mathrm{~m}: 10\end{array}$ \\
\hline $\begin{array}{l}\text { Altura do meio-fio }(H m f) \\
(p=2)\end{array}$ & $\begin{array}{l}H m f>0,18 \mathrm{~m}: 0 \\
H m f<0,10 \mathrm{m:}: 0 \\
0,10 \mathrm{~m} \leq H m f \leq 0,18 \mathrm{~m}: 10\end{array}$ \\
\hline Valor máximo ideal & 320 \\
\hline
\end{tabular}

Tabela 4 - Indicadores do Tema Rebaixos de calçada. FONTE: Adaptado de Cerna [2014]

\begin{tabular}{ll}
\hline Tema: FAIXA DE PEDESTRE & \\
\hline Indicadores e pesos & Critérios de avaliação \\
\hline Largura mínima da faixa de & $L m<3,00 \mathrm{~m}: 0 ;$ \\
travessia de pedestres $(L m)(\mathrm{p}=3)$ & $L m>3,0 \mathrm{~m}: 10$ \\
Estado de manutenção $(\mathrm{p}=3)$ & Ruim: 0; Regular: 5; Bom: \\
& 10 \\
Sinalizado com faixas pintadas & Não: 0; Sim: 10
\end{tabular}

Realização:
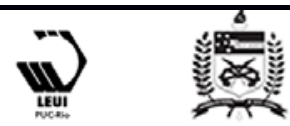
$16^{\circ}$ Ergodesign - Congresso Internacional de Ergonomia e Usabilidade de Interfaces Humano Tecnológica: Produto, Informações Ambientes Construídos e Transporte

$16^{\circ}$ USIHC - Congresso Internacional de Ergonomia e Usabilidade de Interfaces Humano Computador

CINAHPA | 2017 - Congresso Internacional de Ambientes Hipermídia para Aprendizagem.

\begin{tabular}{ll}
\hline Tema: FAIXA DE PEDESTRE & \\
\hline Indicadores e pesos & Critérios de avaliação \\
\hline$(\mathrm{p}=3)$ & \\
Cor da faixa $(\mathrm{p}=3)$ & Branca: 10 ; Outra cor: 0 \\
Presença de iluminação $(\mathrm{p}=3)$ & Não: 0 ; Sim: 10 \\
\hline Valor máximo ideal & $\mathbf{1 5 0}$ \\
\hline
\end{tabular}

Tabela 5 - Indicadores do Tema Faixas de pedestre. FONTE: Adaptado de Cerna [2014]

\begin{tabular}{ll}
\hline Tema: SEMÁFOROS & \\
\hline Indicadores e pesos & Critérios de avaliação \\
\hline $\begin{array}{l}\text { Presença de dispositivo manual } \\
(\mathrm{p}=2)\end{array}$ & Não: 0; Sim: 10 \\
$\begin{array}{l}\text { Altura do dispositivo manual } \\
(\text { Adm })(\mathrm{p}=2)\end{array}$ & $\begin{array}{l}\text { Adm }<0,80 \mathrm{~m}: 0 ; \\
\text { Adm }>1,20 \mathrm{~m}: 0 ;\end{array}$ \\
$\begin{array}{l}\text { Presença de sinal sonoro }(\mathrm{p}=3) \\
\text { Localização dificulta a circulação }\end{array}$ & Não: 0 ; Sim: 10 \\
$\begin{array}{l}(\mathrm{p}=2) \\
\text { Movimentação de pedestre }\end{array}$ & Não: 0 ; Sim: 10 \\
atendida $(\mathrm{p}=3)$ & Não: 0 ; Sim: 10 \\
\hline Valor máximo ideal & $\mathbf{1 2 0}$ \\
\hline
\end{tabular}

Tabela 6 - Indicadores do Tema Semáforos. FONTE: Adaptado de Cerna [2014]

\begin{tabular}{|c|c|}
\hline \multicolumn{2}{|l|}{ Tema: RAMPA } \\
\hline Indicadores e pesos & Critérios de avaliação \\
\hline $\begin{array}{l}\text { Piso com material antiderrapante } \\
(p=3)\end{array}$ & Não: 0; Sim: 10 \\
\hline $\begin{array}{l}\text { Piso com ranhuras horizontais } \\
(\mathrm{p}=3)\end{array}$ & Não: 0; Sim: 10 \\
\hline $\begin{array}{l}\text { Presença de piso tátil alerta (Pta) } \\
(\mathrm{p}=3)\end{array}$ & Não: 0; Sim: 10 \\
\hline $\begin{array}{l}\text { Presença de Pta no início e no } \\
\text { término da rampa }(\mathrm{p}=3)\end{array}$ & Não: 0; Sim: 10 \\
\hline $\begin{array}{l}\text { Cor Pta contrastante com o piso } \\
(p=3)\end{array}$ & Não: 0; Sim: 10 \\
\hline $\begin{array}{l}\text { Largura Pta }(\text { Lpta }) \\
(\mathrm{p}=3)\end{array}$ & $\begin{array}{l}\text { Lpta }<0,25 \mathrm{~m}: 0 \\
\text { Lpta }>0,60 \mathrm{~m}: 5 \\
0,25 \mathrm{~m} \leq \text { Lpta } \leq 0,60 \mathrm{~m}: 10\end{array}$ \\
\hline $\begin{array}{l}\text { Distância entre Pta e ponto de } \\
\text { mudança de plano }(D m p)(\mathrm{p}=3)\end{array}$ & $\begin{array}{l}\text { Dmp >0,32: } 0 \\
D m p \leq 0,32 \mathrm{~m}: 10\end{array}$ \\
\hline $\begin{array}{l}\text { Inclinação longitudinal (il) } \\
(\mathrm{p}=3)\end{array}$ & $\begin{array}{l}5,00 \%>\text { il: } 0 \\
8,33 \%<\text { il: } 0 \\
5,00 \% \geq \text { il } \geq 8,33 \%: 10\end{array}$ \\
\hline $\begin{array}{l}\text { Inclinação transversal (it) } \\
(\mathrm{p}=3)\end{array}$ & $\begin{array}{l}i t>3 \%: 0 \\
\text { it } \leq 3 \%: 10\end{array}$ \\
\hline Largura da rampa $(\operatorname{Lram})(\mathrm{p}=3)$ & Lram $\geq 1,20 \mathrm{~m}: 10$ \\
\hline Valor máximo ideal & 300 \\
\hline
\end{tabular}

Tabela 7 - Indicadores do Tema Rampa. FONTE: Adaptado de Cerna [2014]

Neste artigo foi proposta uma continuidade do método desenvolvido por Cerna [2014], pois o autor realizou apenas a proposta de mensuração de Indicador e Tema. Deste modo, para realizar a análise dos resultados, foi adotada uma forma de avaliação similar à desenvolvida por Bradshaw
[PIRES; GEBARA; MAGAGNIN, 2016], onde cada indicador recebe uma pontuação máxima - ou valor máximo (melhor situação) e uma pontuação mínima "0" (pior situação). Este procedimento é importante para que possamos obter uma escala de valores que permita avaliar se a pontuação encontrada é adequada ou qual é o grau de caminhabilidade do eixo viário, é necessário realizar uma comparação entre a pontuação obtida em campo com a pontuação máxima que este eixo viário poderia atingir.

Na sequencia as notas finais de cada Indicador de um mesmo Tema são somadas e comparadas ao valor máximo ideal do respectivo Tema (Tabela 8). Este cálculo define a caminhabilidade parcial, por Tema, de cada quadra analisada.

Na etapa seguinte, para obtenção do resultado global do recorte espacial, por Tema, o resultado do cálculo do valor máximo ideal global deve ser comparado com o valor global encontrado no recorte espacial. Os resultados devem ser classificados de acordo com a escala de avaliação que varia de "Péssimo" a "Ótimo", da Tabela 8. A classificação final encontrada permite determinar o grau de caminhabilidade global por Tema, no recorte espacial.

\begin{tabular}{|c|c|c|c|c|}
\hline \multicolumn{5}{|c|}{ Classificação das pontuações dos Temas } \\
\hline Temas & $\begin{array}{l}\text { Péssimo } \\
0 \text { a } 25 \%\end{array}$ & $\begin{array}{c}\text { Ruim } \\
26 \text { a } 50 \%\end{array}$ & $\begin{array}{c}\text { Bom } \\
51 \text { a } 75 \%\end{array}$ & $\begin{array}{c}\text { Ótimo } \\
76 \text { a } 100 \%\end{array}$ \\
\hline Calçada & $0-90$ & $91-180$ & $181-270$ & $271-360$ \\
\hline $\begin{array}{l}\text { Ponto de } \\
\text { ônibus }\end{array}$ & $0-82$ & $83-165$ & $166-247$ & $248-330$ \\
\hline $\begin{array}{l}\text { Abrigo de } \\
\text { passageiros }\end{array}$ & $0-30$ & $31-60$ & $61-90$ & $91-120$ \\
\hline $\begin{array}{l}\text { Rebaixo de } \\
\text { calçada }\end{array}$ & $0-80$ & $81-160$ & $161-240$ & $241-320$ \\
\hline $\begin{array}{l}\text { Faixa de } \\
\text { pedestres }\end{array}$ & $0-37$ & $38-75$ & $76-112$ & $113-150$ \\
\hline Semáforos & $0-30$ & $31-60$ & $61-90$ & $91-120$ \\
\hline Rampa & $0-75$ & $76-150$ & $151-225$ & $226-300$ \\
\hline
\end{tabular}

Tabela 8 - Classificação da pontuação dos Temas

A avaliação por Tema permite identificar quais aspectos gerais da infraestrutura do pedestre pode prejudicar a caminhabilidade local, enquanto a avaliação dos Indicadores por Tema permite determinar os elementos pontuais da infraestrutura do pedestre que precisam de adequação por parte
Realização:
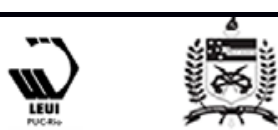
$16^{\circ}$ Ergodesign - Congresso Internacional de Ergonomia e Usabilidade de Interfaces Humano Tecnológica: Produto, Informações Ambientes Construídos e Transporte

$16^{\circ}$ USIHC - Congresso Internacional de Ergonomia e Usabilidade de Interfaces Humano Computador

CINAHPA | 2017 - Congresso Internacional de Ambientes Hipermídia para Aprendizagem.

dos gestores locais.

\section{Resultados e Discussão}

Nesta seção é apresentada a análise dos resultados obtidos a partir da aplicação da auditoria técnica no percurso avaliado.

A Tabela 9 apresenta o resultado da avaliação dos Temas - pontuação máxima ideal e pontuação obtida em campo. Estas pontuações foram multiplicadas pela quantidade de cada Tema encontrado em campo (4 pontos de ônibus/abrigo de passageiros, 7 semáforos, por exemplo). Em destaque, são apresentados os resultados que obtiveram valores em campo inferior a 50\% do valor máximo ideal, a coluna resultado percentual mostra a classificação final, do maior ao menor valor, utilizando a mesma faixa de classificação adotada na Tabela 8.

\begin{tabular}{lccc|}
\hline \multicolumn{1}{c}{ Temas } & $\begin{array}{c}\text { Valor } \\
\text { máximo } \\
\text { ideal }\end{array}$ & $\begin{array}{c}\text { Valor } \\
\text { obtido em } \\
\text { campo }\end{array}$ & $\begin{array}{c}\text { Resultado } \\
\text { Percentual }\end{array}$ \\
\hline Calçadas & 8000 & 5750 & $71,88 \%$ \\
\hline Pontos de ônibus & $\mathbf{1 3 6 0}$ & $\mathbf{4 4 0}$ & $\mathbf{3 2 , 3 5 \%}$ \\
\hline Abrigos de passageiros & 480 & 420 & $87,50 \%$ \\
Rebaixos de calçada & 6950 & 5350 & $76,98 \%$ \\
Faixas de pedestre & 3750 & 3450 & $92,00 \%$ \\
Semáforos & 840 & 430 & $51,19 \%$ \\
Rampa & 250 & 130 & $52,00 \%$ \\
\hline
\end{tabular}

Tabela 9 - Resultado do somatório dos indicadores de cada tema analisado

Dentre os Temas avaliados, os pontos de ônibus obtiveram o pior valor calculado (32,35\%), enquanto as calçadas, os abrigos dos pontos, os rebaixos de calçada e as faixas de pedestre obtiveram resultados próximos da infraestrutura considerada ideal, entre $70 \%$ e $100 \%$. Os semáforos e a rampa obtiveram valores próximos de $50 \%$, podendo ser considerados inadequados aos pedestres.

Os valores encontrados no Tema calçadas (71,88\%) estão relacionados à presença dos elementos de infraestrutura mínimos (faixa livre e faixa de serviço) em todos os trechos de calçadas avaliados. Estes trechos são desobstruídos de obstáculos, com larguras adequadas, faixas de serviço próximas ao meio fio e com presença de iluminação pública.

As superfícies das calçadas, em sua maioria (95\%), são firmes e estáveis e antiderrapantes, porém apenas $65 \%$ eram regulares e $70 \%$ sem desníveis, enquanto $40 \%$ eram de material de fácil reposição. Foram observadas calçadas com algumas partes sem pavimentação; 85\% das calçadas possuem altura de meio fio adequada e estão niveladas com os lotes contíguos.

Devido à topografia acidentada da região, apenas $60 \%$ das calçadas possuem inclinação longitudinal adequada, enquanto $90 \%$ das calçadas têm inclinação transversal dentro das dimensões apropriadas. As placas de sinalização para os veículos estavam, em sua maioria, fora da altura recomendada de $2,10 \mathrm{~m}$, portanto apenas $35 \%$ das calçadas pontuaram neste indicador. Outro fator que prejudica a microacessibilidade local é a pouca arborização, apenas $20 \%$ das calçadas possuíam árvores, sendo que menos da metade oferece sombreamento e frescor (Tabela 10).

\begin{tabular}{|lccc|}
\hline Indicadores do Tema Calçada & $\begin{array}{c}\text { Valor } \\
\text { máx. } \\
\text { ideal }\end{array}$ & $\begin{array}{c}\text { Valor } \\
\text { obtido em } \\
\text { campo }\end{array}$ & $\begin{array}{c}\text { Resultado } \\
\text { Percentual }\end{array}$ \\
\hline Elementos mínimos da calçada & 200 & 200 & $100,00 \%$ \\
Localização faixa de serviço & 200 & 200 & $100,00 \%$ \\
Largura de faixa livre ou passeio & 400 & 400 & $100,00 \%$ \\
Superfície regular & 400 & 260 & $65,00 \%$ \\
Superfície sem desníveis & 600 & 420 & $70,00 \%$ \\
Superfície firme e estável & 600 & 570 & $95,00 \%$ \\
Superfície anti derrapante & 600 & 570 & $95,00 \%$ \\
\hline Superfície de fácil reposição & $\mathbf{2 0 0}$ & $\mathbf{8 0}$ & $\mathbf{4 0 , 0 0 \%}$ \\
\hline Inclinação longitudinal & 400 & 240 & $60,00 \%$ \\
Inclinação transversal & 600 & 540 & $90,00 \%$ \\
\hline Altura livre de obstáculos & $\mathbf{4 0 0}$ & $\mathbf{1 4 0}$ & $\mathbf{3 5 , 0 0 \%}$ \\
\hline Faixa desobstruída e isenta de & 600 & 600 & $100,00 \%$ \\
interferências & & & \\
\hline Arborização vias arteriais & $\mathbf{4 0 0}$ & $\mathbf{8 0}$ & $\mathbf{2 0 , 0 0 \%}$ \\
\hline Altura de meio-fio & 400 & 340 & $85,00 \%$ \\
\hline Nivelação com a calçada do lote & 600 & 510 & $85,00 \%$ \\
contíguo & & & \\
Presença de iluminação & 600 & 600 & $100,00 \%$ \\
\hline
\end{tabular}

Tabela 10 - Resultado do somatório dos indicadores das calçadas

A baixa pontuação dos pontos de ônibus ocorre devido à ausência de sinalização de piso tátil de 
$16^{\circ}$ Ergodesign - Congresso Internacional de Ergonomia e Usabilidade de Interfaces Humano Tecnológica: Produto, Informações Ambientes Construídos e Transporte

$16^{\circ}$ USIHC - Congresso Internacional de Ergonomia e Usabilidade de Interfaces Humano Computador

CINAHPA | 2017 - Congresso Internacional de Ambientes Hipermídia para Aprendizagem.

alerta ao longo do meio fio das calçadas do eixo viário e nos locais de embarque e desembarque, ausência de placa de sinalização de ponto de ônibus, de lixeira, de árvores, de marcações delimitadoras nas vias e de baías para parada dos ônibus e a dimensão de reentrância destas baías. Outro ponto negativo refere-se a presença da rampa de acesso e painel informativo do transporte público em apenas dois pontos de ônibus.

\begin{tabular}{|c|c|c|c|}
\hline $\begin{array}{c}\text { Indicadores do Tema Ponto } \\
\text { de Ônibus }\end{array}$ & $\begin{array}{c}\text { Valor } \\
\text { máximo } \\
\text { ideal }\end{array}$ & $\begin{array}{c}\text { Valor } \\
\text { obtido em } \\
\text { campo }\end{array}$ & $\begin{array}{r}\text { Resultado } \\
\text { Percentual }\end{array}$ \\
\hline $\begin{array}{l}\text { Sinalização tátil de alerta ao } \\
\text { longo do meio-fio }\end{array}$ & 120 & $\mathbf{0}$ & $0,00 \%$ \\
\hline $\begin{array}{l}\text { Piso tátil direcional no local } \\
\text { de embarque/ desembarque }\end{array}$ & 120 & $\mathbf{0}$ & $0,00 \%$ \\
\hline $\begin{array}{l}\text { Comprimento mínimo de } \\
\text { calçada }\end{array}$ & 80 & 60 & $75,00 \%$ \\
\hline Largura mínima de calçada & 80 & 80 & $100,00 \%$ \\
\hline Presença de rampa de acesso & 80 & 40 & $50,00 \%$ \\
\hline Presença de meio-fio & 120 & 120 & $100,00 \%$ \\
\hline $\begin{array}{l}\text { Presença placa de } \\
\text { sinalização de ponto de } \\
\text { ônibus }\end{array}$ & 120 & $\mathbf{0}$ & $0,00 \%$ \\
\hline $\begin{array}{l}\text { Presença de ponto de } \\
\text { iluminação pública }\end{array}$ & 120 & 120 & $100,00 \%$ \\
\hline Presença de lixeira & 40 & $\mathbf{0}$ & $0,00 \%$ \\
\hline Presença de árvore & 80 & $\mathbf{0}$ & $0,00 \%$ \\
\hline $\begin{array}{l}\text { Presença de marcações } \\
\text { delimitadoras nas vias }\end{array}$ & 120 & $\mathbf{0}$ & $0,00 \%$ \\
\hline Presença de baia & 120 & $\mathbf{0}$ & $0,00 \%$ \\
\hline $\begin{array}{l}\text { Profundidade de reentrância } \\
\text { nas calçadas }\end{array}$ & 120 & $\mathbf{0}$ & $\mathbf{0 , 0 0 \%}$ \\
\hline $\begin{array}{l}\text { Presença de painel } \\
\text { informativo do Transporte } \\
\text { Público }\end{array}$ & 40 & 20 & $50,00 \%$ \\
\hline
\end{tabular}

Tabela 11 - Resultado do somatório dos indicadores dos pontos de ônibus

O comprimento mínimo das calçadas (75\%) e a largura mínima das calçadas (100\%) (para presença dos pontos de ônibus), a presença de meio fio (100\%) e a presença de iluminação pública (100\%) foram os indicadores que obtiveram maior pontuação na auditoria técnica (Tabela 11).

\begin{tabular}{lccc}
\hline $\begin{array}{c}\text { Indicadores do Tema abrigo } \\
\text { de passageiro }\end{array}$ & $\begin{array}{c}\text { Valor } \\
\text { máximo } \\
\text { ideal }\end{array}$ & $\begin{array}{c}\text { Valor } \\
\text { obtido em } \\
\text { campo }\end{array}$ & $\begin{array}{c}\text { Resultado } \\
\text { Percentual }\end{array}$ \\
\hline Presença de assentos fixos & 80 & 80 & $100,00 \%$ \\
Espaço para cadeirantes & 80 & 80 & $100,00 \%$ \\
$\begin{array}{l}\text { Espaço cadeirantes próximo aos } \\
\text { assentos }\end{array}$ & 80 & 80 & $100,00 \%$ \\
\hline
\end{tabular}

\begin{tabular}{lccc}
\hline $\begin{array}{c}\text { Indicadores do Tema abrigo } \\
\text { de passageiro }\end{array}$ & $\begin{array}{c}\text { Valor } \\
\text { máximo } \\
\text { ideal }\end{array}$ & $\begin{array}{c}\text { Valor } \\
\text { obtido em } \\
\text { campo }\end{array}$ & $\begin{array}{c}\text { Resultado } \\
\text { Percentual }\end{array}$ \\
\hline $\begin{array}{l}\text { Largura espaço cadeirantes } \\
\text { Cumprimento espaço }\end{array}$ & 80 & 60 & $75,00 \%$ \\
cadeirantes & 80 & 40 & $50,00 \%$ \\
Presença de cobertura & 80 & 80 & $100,00 \%$ \\
\hline
\end{tabular}

Tabela 12 - Resultado do somatório dos indicadores dos abrigos de passageiros

Conforme mencionado anteriormente, todos os pontos de ônibus possuem abrigos de passageiros com cobertura e assentos fixos, com espaço para usuários de cadeiras de rodas nas proximidades; em geral estes espaços estavam acima das dimensões recomendadas. Na Tabela 12 são apresentados os valores obtidos na auditoria técnica deste Tema.

Na avaliação do Tema Rebaixos da calçada, observou-se que todos os rebaixos existentes estavam localizados em local de travessia de pedestres, na direção do fluxo de pedestres, com desnível zero entre rebaixo e leito carroçável e piso antiderrapante, com largura mínima apropriada da calçada. A maioria dos rebaixos de calçada possuem inclinações transversal e longitudinal de acordo com as recomendações técnicas da NBR 9050 [ABNT, 2015], ou seja, estão alinhados entre si, com a largura da faixa livre em frente ao rebaixo acima de $80 \mathrm{~cm}$ e altura do meio fio adequada, como mostrado na Tabela 13.

Considerando-se dois rebaixos de calçada por esquina, deveriam haver setenta rebaixos no percurso, porém no local existem apenas 30\% desse total. Portanto, mesmo tendo obtido um bom somatório $(76,98 \%)$ os rebaixos de calçada representam um problema no local, por sua presença descontínua.

\begin{tabular}{lccc}
\hline \multicolumn{1}{c}{$\begin{array}{c}\text { Indicadores do Tema } \\
\text { rebaixo de calçada }\end{array}$} & $\begin{array}{c}\text { Valor } \\
\text { máximo } \\
\text { ideal }\end{array}$ & $\begin{array}{c}\text { Valor } \\
\text { obtido em } \\
\text { campo }\end{array}$ & $\begin{array}{c}\text { Resultado } \\
\text { Percentual }\end{array}$ \\
\hline $\begin{array}{l}\text { Localizado em local de } \\
\text { travessias de pedestres }\end{array}$ & 660 & 660 & $100,00 \%$ \\
$\begin{array}{l}\text { Desnível entre parte inferior } \\
\text { do RC e o leito carroçável }\end{array}$ & 440 & 440 & $100,00 \%$ \\
$\begin{array}{l}\text { Construídos na direção do } \\
\text { fluxo de pedestres }\end{array}$ & 220 & 220 & $100,00 \%$ \\
$\begin{array}{l}\text { Os RC em lados opostos da } \\
\text { via alinhados entre si }\end{array}$ & 570 & 450 & $78,95 \%$ \\
\hline
\end{tabular}

Realização:

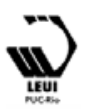




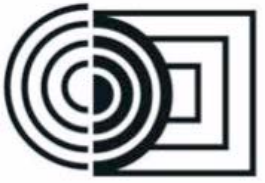

ERGODESIGN USIHC CINAHPA

\begin{tabular}{|c|c|c|c|}
\hline $\begin{array}{l}\text { Indicadores do Tema } \\
\text { rebaixo de calçada }\end{array}$ & $\begin{array}{c}\text { Valor } \\
\text { máximo } \\
\text { ideal }\end{array}$ & $\begin{array}{c}\text { Valor } \\
\text { obtido em } \\
\text { campo }\end{array}$ & $\begin{array}{l}\text { Resultado } \\
\text { Percentual }\end{array}$ \\
\hline Inclinação longitudinal do RC & 440 & 420 & $95,45 \%$ \\
\hline Inclinação transversal do RC & 440 & 420 & $95,45 \%$ \\
\hline Presença de piso tátil de alerta & 660 & 330 & $50,00 \%$ \\
\hline $\begin{array}{l}\text { Largura do piso tátil de alerta } \\
\text { de RC }\end{array}$ & 660 & 330 & $50,00 \%$ \\
\hline $\begin{array}{l}\text { Distância do RC da curva da } \\
\text { esquina }\end{array}$ & 660 & 90 & $13,64 \%$ \\
\hline $\begin{array}{l}\text { Largura faixa livre em frente } \\
\text { ao RC }\end{array}$ & 660 & 570 & $86,36 \%$ \\
\hline $\begin{array}{l}\text { Superfície piso com material } \\
\text { antiderrapante }\end{array}$ & 660 & 660 & $100,00 \%$ \\
\hline $\begin{array}{l}\text { Largura mínima de calçada } \\
\text { para RC }\end{array}$ & 440 & 440 & $100,00 \%$ \\
\hline Altura do meio-fio & 440 & 320 & $72,73 \%$ \\
\hline
\end{tabular}

Tabela 13- Resultado do somatório dos indicadores dos rebaixos de calçada

Cerna [2014] baseou-se na Lei Distrital

$\mathrm{N}^{\circ} 2.105 / 1998$ e NBR 9050 para determinar a distância mínima que os rebaixos de calçada devem estar dos pontos de curvas de veículos. Somente $13,64 \%$ dos rebaixos do local avaliado cumprem este parâmetro; 50\% dos rebaixos possuem piso tátil de alerta com as dimensões apropriadas.

Das 37 travessias do percurso, 25 são sinalizadas com faixas de pedestre. Destas, todas têm presença de iluminação pública, são faixas zebradas na cor branca e dentro do padrão mínimo de $3 \mathrm{~m}$ de largura. O menor valor obtido em campo foi do estado de manutenção das faixas (60\%), foram observados faixas de pedestres descoloridas e com buracos no leito carroçável (Tabela 14).

\begin{tabular}{lccc}
\hline $\begin{array}{c}\text { Indicadores do Tema faixa de } \\
\text { pedestre }\end{array}$ & $\begin{array}{c}\text { Valor } \\
\text { máximo } \\
\text { ideal }\end{array}$ & $\begin{array}{c}\text { Valor } \\
\text { obtido em } \\
\text { campo }\end{array}$ & $\begin{array}{c}\text { Resultado } \\
\text { Percentual }\end{array}$ \\
\hline $\begin{array}{l}\text { Largura mínima da faixa de } \\
\text { pedestres }\end{array}$ & 750 & 660 & $100,00 \%$ \\
Estado de manutenção & 750 & 345 & $60,00 \%$ \\
Sinalizado com faixas pintadas & 750 & 660 & $100,00 \%$ \\
Cor da faixa & 750 & 660 & $100,00 \%$ \\
Presença de iluminação & 750 & 660 & $100,00 \%$ \\
\hline
\end{tabular}

Tabela 14 - Resultado do somatório dos indicadores das faixas de pedestres

No percurso avaliado foram encontrados sete semáforos. Nenhum possuía sinal sonoro de alerta para deficientes visuais e apenas dois (28,57\%) contavam com dispositivo manual com altura $16^{\circ}$ Ergodesign - Congresso Internacional de Ergonomia e Usabilidade de Interfaces Humano Tecnológica: Produto, Informações Ambientes Construídos e Transporte

$16^{\circ}$ USIHC - Congresso Internacional de Ergonomia e Usabilidade de Interfaces Humano Computador

CINAHPA | 2017 - Congresso Internacional de Ambientes Hipermídia para Aprendizagem.

dentro dos parâmetros determinados. A localização dos semáforos não dificulta a circulação dos pedestres e atendem a estes deslocamentos (Tabela 15).

\begin{tabular}{|c|c|c|c|}
\hline $\begin{array}{l}\text { Indicadores do Tema } \\
\text { semáforo }\end{array}$ & $\begin{array}{c}\text { Valor } \\
\text { máximo } \\
\text { ideal }\end{array}$ & $\begin{array}{c}\text { Valor } \\
\text { obtido em } \\
\text { campo }\end{array}$ & $\begin{array}{l}\text { Resultado } \\
\text { Percentual }\end{array}$ \\
\hline $\begin{array}{l}\text { Presença de dispositivo } \\
\text { manual }\end{array}$ & 140 & 40 & $28,57 \%$ \\
\hline Altura do dispositivo manual & 140 & 40 & $28,57 \%$ \\
\hline Presença de sinal sonoro & 210 & $\mathbf{0}$ & $0,00 \%$ \\
\hline $\begin{array}{l}\text { Localização dificulta a } \\
\text { circulação }\end{array}$ & 140 & 140 & $100,00 \%$ \\
\hline $\begin{array}{l}\text { Movimentação de pedestre } \\
\text { atendida }\end{array}$ & 210 & 210 & $100,00 \%$ \\
\hline
\end{tabular}

Tabela 15 - Resultado do somatório dos indicadores dos semáforos

A rampa obteve apenas $50 \%$ do somatório total, pois a inclinação longitudinal está maior do que os parâmetros indicados na metodologia (ente 5\% e 8,33\%); não há espaço para mudança de trajeto no começo e no fim da rampa e não foram encontrados os seguintes elementos: piso tátil de alerta e ranhuras horizontais no piso (Tabela 16).

\begin{tabular}{|c|c|c|c|}
\hline Indicadores do Tema Rampa & $\begin{array}{c}\text { Valor } \\
\text { máximo } \\
\text { ideal }\end{array}$ & $\begin{array}{c}\text { Valor } \\
\text { obtido em } \\
\text { campo } \\
\end{array}$ & $\begin{array}{l}\text { Resultado } \\
\text { Percentual }\end{array}$ \\
\hline $\begin{array}{l}\text { Piso com material } \\
\text { antiderrapante }\end{array}$ & 30 & 30 & $100,00 \%$ \\
\hline $\begin{array}{l}\text { Piso com ranhuras } \\
\text { horizontais }\end{array}$ & 10 & $\mathbf{0}$ & $0,00 \%$ \\
\hline $\begin{array}{l}\text { Presença de piso tátil alerta } \\
\text { (Pta) }\end{array}$ & 30 & $\mathbf{0}$ & $0,00 \%$ \\
\hline $\begin{array}{l}\text { Presença de Pta no início e no } \\
\text { término da rampa }\end{array}$ & 30 & 30 & $100,00 \%$ \\
\hline $\begin{array}{l}\text { Cor Pta contrastante com o } \\
\text { piso }\end{array}$ & 10 & 10 & $100,00 \%$ \\
\hline Largura Pta (Lpta) & 10 & 10 & $100,00 \%$ \\
\hline Dist. Pta e mudança de plano & 30 & $\mathbf{0}$ & $0,00 \%$ \\
\hline Inclinação longitudinal & 20 & $\mathbf{0}$ & $\mathbf{0 , 0 0 \%}$ \\
\hline Inclinação transversal & 30 & 30 & $100,00 \%$ \\
\hline Largura da rampa & 20 & 20 & $100,00 \%$ \\
\hline
\end{tabular}

Tabela 16 - Resultado do somatório dos indicadores da rampa

As Figuras 2 e 3 apresentam os principais problemas encontrados no recorte espacial.

Na Figura 2, primeira parte do mapa, observa-se que ao sair do ponto de ônibus da Av. Nações Unidas, é preciso atravessar para a Praça da Paz 


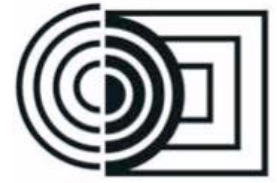

ERGODESIGN USIHC CINAHPA

(face de quadra 18), pois não há calçadas para os pedestres ao longo da avenida, o que leva muitos usuários a andarem pelo canteiro lateral ou mesmo na própria rua, para reduzir a distância e tempo de deslocamento. Além disso, algumas faixas de pedestre estão descoloridas, há ausência de rebaixos de calçada ao longo do percurso e buracos no leito carroçável, o que dificulta o acesso de pessoas com mobilidade reduzida.

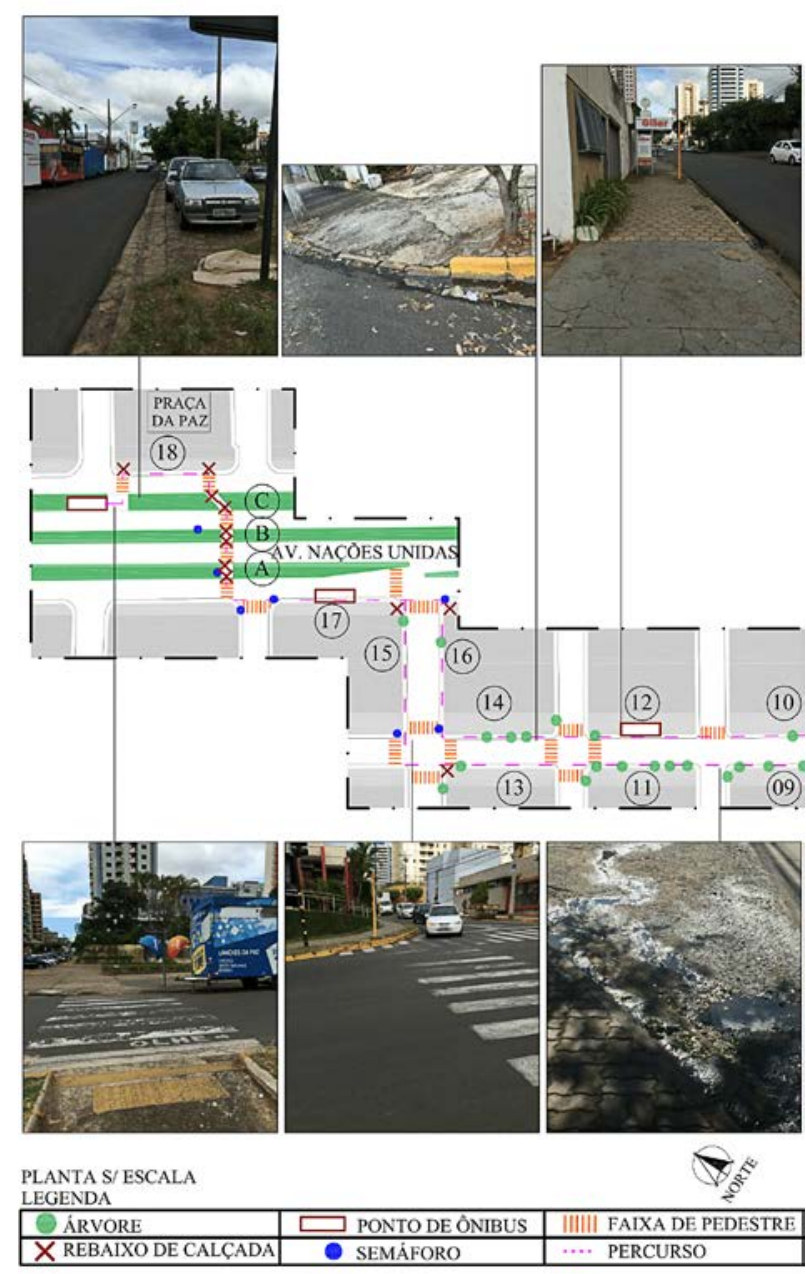

Figura 2 - Parte 01 do mapa elaborado a partir de levantamento em campo do percurso analisado

Na Figura 3, continuação do mapa anterior, observa-se a má conservação das calçadas de terrenos baldios e do estacionamento dentro do lote. Já as calçadas em frente aos comércios possuem melhor qualidade. Na Rua Henrique Savi $16^{\circ}$ Ergodesign - Congresso Internacional de Ergonomia e Usabilidade de Interfaces Humano Tecnológica: Produto, Informações Ambientes Construídos e Transporte

$16^{\circ}$ USIHC - Congresso Internacional de Ergonomia e Usabilidade de Interfaces Humano Computador

CINAHPA | 2017 - Congresso Internacional de Ambientes Hipermídia para Aprendizagem. há uma quantidade menor de rebaixos de calçada e faixas de pedestre do que na Av. Nações Unidas e seu entorno; nas proximidades do Bauru Shopping, os pequenos comércios e serviços estão mais concentrados, refletindo na melhoria da condição do piso das calçadas, do leito carroçável e presença de faixas de pedestre.

Em suma, a aplicação da vistoria técnica apontou que a microacessibilidade local é reduzida pela má qualidade dos pontos de ônibus, rampa e semáforos, enquanto as calçadas, abrigos de passageiros, rebaixos de calçada e faixas de pedestres contribuem para a qualidade do local. Contudo, as ruas e travessias não são sinalizadas com piso tátil de alerta e direcional (presentes apenas em alguns rebaixos de calçadas), os semáforos não possuem sinal sonoro e não há sinalização voltada aos pedestres.

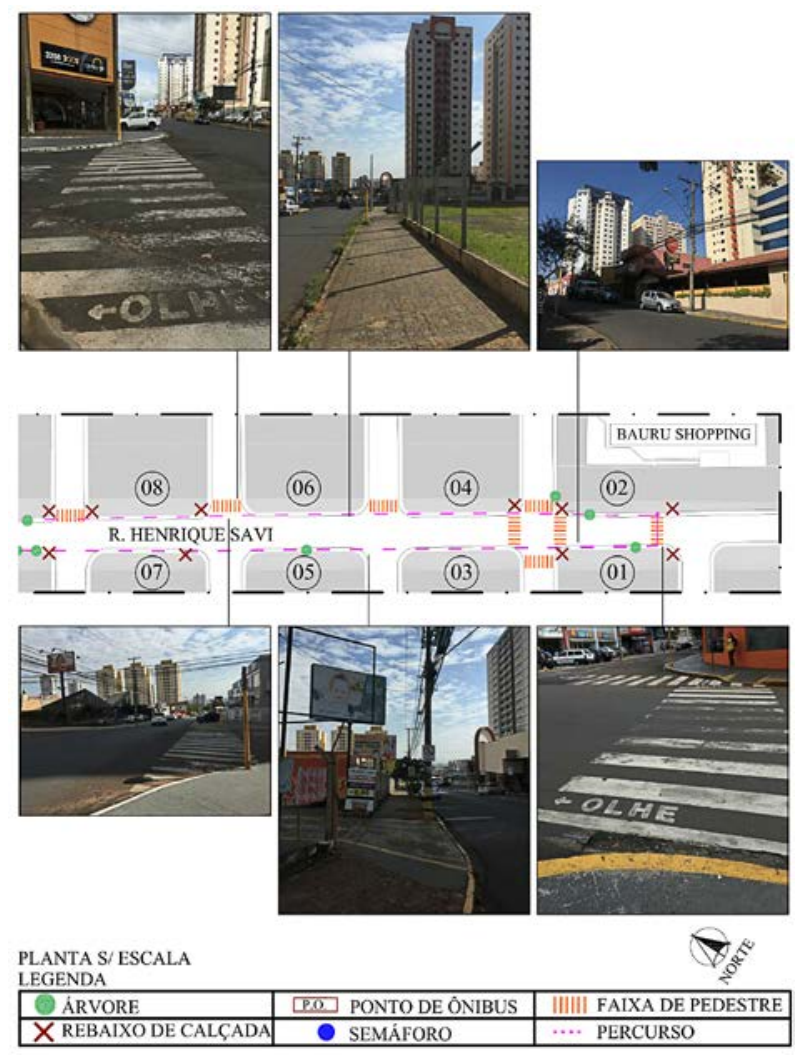

Figura 3 - Parte 02 do mapa elaborado a partir de levantamento em campo do percurso analisado
Realização:

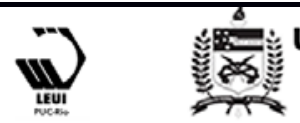


$16^{\circ}$ Ergodesign - Congresso Internacional de Ergonomia e Usabilidade de Interfaces Humano Tecnológica: Produto, Informações Ambientes Construídos e Transporte

$16^{\circ}$ USIHC - Congresso Internacional de Ergonomia e Usabilidade de Interfaces Humano Computador

Entre os poucos rebaixos de calçadas existentes no percurso todos são compostos de materiais antiderrapantes, mas a grande maioria estava posicionada nas curvas das esquinas sem as dimensões recomendadas pelas NBR 9050 [ABNT, 2015] e não diferenciados por cores contrastantes.

As faixas de pedestre, quando presentes, apresentaram pintura desgastada e buracos no leito carroçável; apesar das calçadas possuírem largura efetiva apropriada, algumas estavam desniveladas e irregulares, além da ausência de arborização que proporcionasse sombra e frescor. Os pontos de ônibus/abrigos de passageiros eram cobertos e com assentos fixos e espaço para cadeirantes, mas sem lixeiras, piso tátil de alerta e direcional, sinalização horizontal e vertical, baías para parada do ônibus e os painéis informativos, com informações insuficientes.

Nota-se que muitos dos indicadores foram avaliados somente por sua presença no meio urbano, sem de fato mensurar sua qualidade, pois foi respeitada a metodologia proposta por Cerna [2014]. Este é o caso da iluminação pública, assentos fixos e cobertura nos abrigos de passageiros. Faz-se necessário uma revisão das tabelas de auditoria técnica para que os critérios sejam avaliados também por sua qualidade e não somente pela presença/ausência.

\section{Considerações Finais}

A aplicação do método de auditoria técnica proposto neste artigo permitiu mensurar a caminhabilidade a partir da qualidade das calçadas, rebaixos de calçada, pontos de ônibus, abrigos de passageiros, semáforos, faixas de pedestre e rampa. Os resultados encontrados apontam para a validade do método proposto. No entanto, para consolidação desta proposta sugere-se sua aplicação em outros recortes espaciais.

Entre os Temas, os pontos de ônibus requerem maior atenção por parte da administração pública (melhoria das informações disponíveis, entre outros), seguidos pelos semáforos (não apenas inserção de facilidades aos portadores de deficiência, mas também com priorização do pedestre com tempo de travessia liberado antes dos veículos, por exemplo) e pela rampa, observando as inclinações adequadas, segundo a NBR 9050 [ABNT, 2015]. Além do acréscimo de faixas de pedestre e rebaixo de calçadas no entorno do shopping center. Alguns indicadores que, se alterados, podem contribuir para a caminhabilidade local, são: material do piso das calçadas (inserir materiais de fácil reposição); arborização, para incentivo do modo a pé; inserção de sinalização tátil, não apenas nos pontos de ônibus, mas também rebaixos de calçada; manutenção do leito carroçável e pintura das faixas de pedestre, entre outros.

A boa qualidade da acessibilidade nos espaços públicos gera igualdade entre os habitantes, pois todos passam a usufruir das mesmas oportunidades; além disso, com a melhoria da caminhabilidade, há o incentivo do modo de deslocamento a pé. Espera-se que este diagnóstico torne possível a realização de melhorias na mobilidade urbana que incentivem o deslocamento a pé e por transporte público. Este instrumento é de fácil utilização e pode ser replicado em outros percursos por parte de órgãos públicos e administrações municipais.

\section{BIBLIOGRAFIA}

ABNT (2015). NBR 9050: 2015 - Acessibilidade a edificações, mobiliário, espaços e equipamentos urbanos. ASSOCIAÇÃO BRASILEIRA DE NORMAS TÉCNICAS. Rio de Janeiro.

BOARNET, M.; DAY, K.; ALFONZO M.; FORSYTH A. The Irvine-Minnesota Inventory to measure built environments - reliability testing.

American Journal of Preventive Medicine. v. 30, p. 153-159. 2006.

CERNA, N. S. S. Contribuição para modelagem de um sistema de avaliação da qualidade dos elementos de infraestrutura de mobilidade urbana. Dissertação (Mestrado). Programa de Pós-
Realização:
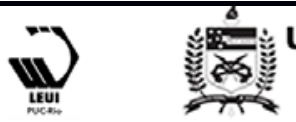


\section{$16^{\circ}$}

ERGODESIGN USIHC CINAHPA $16^{\circ}$ Ergodesign - Congresso Internacional de Ergonomia e Usabilidade de Interfaces Humano Tecnológica: Produto, Informações Ambientes Construídos e Transporte

$16^{\circ}$ USIHC - Congresso Internacional de Ergonomia e Usabilidade de Interfaces Humano Computador

CINAHPA | 2017 - Congresso Internacional de Ambientes Hipermídia para Aprendizagem.
Graduação em Transporte. Universidade de Brasília, 2014.

DAY, K.; BOARNET, M.; ALFONZO, M.; FORSYTH, A. The Irvine Minnesota Inventory to measure built environments: Development.

American Journal of Preventive Medicine v. 30, p. 144-152. 2006.

FERRAZ, A. C. P.; TORRES, I. G. E. Transporte Público Urbano. 2. ed. São Carlos: Rima, 2004.

FONTENELLE, R. B.; LIBARDONI, V. S.; ZAMPIERI, F. L.; BINS ELY, V. H. M. Avaliação da qualidade das calçadas relacionada com o fluxo de pedestres no centro de Florianópolis. In: NUTAU - Núcleo de Pesquisa em Tecnologia da Arquitetura e Urbanismo, 2008, São Paulo. Métis (UCS), 2008.

GEHL, J. Cidades para pessoas. 3 ed. São Paulo: Perspectiva, 2015.

GORI, S.; NIGRO, M.; PETRELLI, M.

Walkability Indicators for Pedestrian-Friendly Design. Journal of the Transportation Research Board, 2464: 38-45. 2014.

GUO, Z.; LOO, B. PY. Pedestrian environment and route choice: evidence from New York City and Hong Kong. Journal of Transport Geography, 28, 124-136. 2013.

KHISTY, C. J. (1994) Evaluation of pedestrian facilities: beyond the level of service concept.

Transportation Research Record 1438. p. 45-50. 1994.

LANCHOTI, J. A; BRUNA, G. C. Desempenho da Mobilidade no espaço urbano Construído na cidade de Ribeirão Preto - SP - Uma Proposta de Avaliação. Em Ornstein, Sheila Walbe; Almeida PRADO, Adriana Romero de; Lopes, Maria Elisabete (orgs). Desenho Universal: Caminhos da acessibilidade no Brasil. São Paulo: Annablume, 2010. p 197-208.

LANDIS, B. W.; VATTIKUTI, V. R.;
OTTENBERG, R. M.; MCLEOD, D. S.;

GUTTENPLAN, M. Modelling the roadside walking environment: A pedestrian level of service. Transportation Research Record. 1773, p. 82-88. 2001.

MORI, M.; TSUKAGUCHI, H. A new method for the evaluation of level of service in pedestrian facilities. Transportation Research A. v. 21A. No 3. p. 223-234. 1987.

MURALEETHARAN, T.; ADACHI, T.; HAGIWARA, T.; KAGAYA, S. Method to determined overall Level of Service of pedestrians on sidewalk and crosswalks based on total utility value, TRB 2004 Annual Meeting. 2004.

PIRES, I. B.; GEBARA, T. R. J.; MAGAGNIN, R. C. Métodos para avaliação da Caminhabilidade. In: FONTES, M. S. G. C.; FARIA, J. R. G. (Org.).

Ambiente construído e sustentabilidade. Tupã: ANAP, 2016. p. 110-135.

SARKAR, S. Qualitative evaluation of comfort needs in urban walkways in major activity centers. Anais... TRB 2003 Annual Meeting. 2003.

SPECK, J. Cidade caminhável. 1 ed. São Paulo: Perspectiva, 2016.

YOSHIDA, D. M.; ALONGE, F. A.; MAGAGNIN, R. C. Qualidade da acessibilidade espacial do pedestre em um eixo comercial. In: Anais... $7^{\circ}$ Congresso Luso Brasileiro para o Planejamento Urbano e Regional, Integrado e Sustentável. Maceió: Viva Editora, 2016. p. 01-12.
Realização:

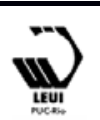

